\title{
Intradiscal Pressure Response to Low-Frequency Cyclic Loading*
}

\author{
Kazuaki KATAGIRI**, Shigeru TADANO***, \\ Avinash G. PATWARDHAN****, Robert M. HAVEY**** \\ and Alexander J. GHANAYEM****
}

\begin{abstract}
Epidemiological studies have suggested that because of their frequent exposure to mechanical vibration, bus and truck drivers are especially susceptible to disc disorders. It has been reported that drivers of such vehicles are subjected to low-frequency vibration up to $6 \mathrm{~Hz}$. The intervertebral disc regulates the viscoelastic properties of spinal segments. The intradiscal pressure will play an important role in the mechanical response of a spinal segment to vibrations. While previous studies have made direct in vivo measurements of intradiscal pressure under static conditions, no data has been reported on intradiscal pressure response to vibration loading under either in vivo or ex vivo conditions. The present study is to measure the intradiscal pressure response to cyclic loading in a physiological saline solution simulating in vivo conditions. The effect of mean load, amplitude and frequency of cyclic loading on the intradiscal pressure response was examined using calf lumbar spinal segments. The experiment employed mean loads of 20,60 , and $100 \mathrm{~N}$ with amplitudes of 10,15 , and 20 $\mathrm{N}$ and compared the low-frequency effects of $0.05,0.5$ and $5 \mathrm{~Hz}$. The mean load was applied for one hour before the cyclic loading test, in order to consider the equilibrium intradiscal pressure. Therefore, it was confirmed that the relationships of load versus displacement, and load versus intradiscal pressure were affected by the mean load and the frequency of cyclic loading.
\end{abstract}

Key Words: Biomechanics, Medical Engineering, Intervertebral Disc, Intradiscal Pressure,Vibration Response

\section{Introduction}

Epidemiologic studies ${ }^{(1)-(4)}$ have indicated that truck or bus drivers are especially susceptible to disc disorders of lumbar spine, because of frequent exposure to mechanical vibration from the body of a vehicle. Wilder et al ${ }^{(5)}$ reported that drivers of such large vehicles are subjected to low-frequency vibrations up to $6 \mathrm{~Hz}$ in motion at local street or highway. The driver usually takes the sitting position. The

* Received 9th April, 1999. Japanese original: Trans. Jpn. Soc. Mech. Eng., Vol.64, No.625, A (1998), p. 2429-2434 (Received 23rd June, 1997)

** Sumitomo Precision Products Co. Ltd., Fuso chou 1-4, Amagasaki 660-0891, Japan

*** Division of Mechanical Science, Hokkaido University, Kita-ku, N-13, W-8, Sapporo 060-8628, Japan. E-mail : tadano@eng.hokudai.ac.jp

**** Hines VA Rehabilitation R \& D Center and Loyola University Chicago, Medical Center, Illinois, USA low-frequency vibration from the seat transmits to the spine through pelvis. The spine is the structure connected with many vertebrae and intervertebral discs in series. The absorbing ability of the spine against outer vibration is undertaken by the disc which regulates the viscoelastic properties of soft tissues. In order to investigate the mechanism of low back pain induced by the disc disorders at lumbar spine, the basic biomechanical study is much important on loading response of lumbar spine. The intervertebral disc consists of two distinct parts: the nucleus pulposus which is located in the central portion of the disc is a mucoprotein gel and the annulus is fibrosus tissue in concentric laminated bands. An appropriate intradiscal pressure (IDP) exists in the nucleus pulposus. It is thought that the intradiscal pressure response plays an important role in the mechanical response of a disc to low-frequency vibration.

In previous studies, direct in vivo measurements 
of lumbar intradiscal pressures have been done under static conditions. The intervertebral pressure depends on posture or motion of the body. Nachemson et al. ${ }^{(6)}$ reported that intradiscal pressures were the highest value of $1 \mathrm{MPa}$ in the sitting position, and about 30\% less in the standing and about $50 \%$ less in the reclining position. Pope and Andersson et al. ${ }^{(7)}$ measured the intradiscal pressure in various sitting positions with or without backrest, arm on desk and arm hanging. They reported that the intradiscal pressure in these positions was within the range of 350 to $550 \mathrm{kPa}$. Although these surveys have suggested that the lowfrequency vibration would induce the most serious risk factors to low-back pain syndrome for the driver, the intradiscal pressure response to vibration loading has not been reported yet under either in vivo or ex vivo conditions.

The intervertebral disc is the largest avascular organ in the human body. The nutrition transport to disc tissue does not depend on blood circulation. It has pointed out that the intradiscal pressure change in daily life is one of the motive forces to promote the nutrition supply for the $\operatorname{disc}^{(8),(9)}$. The intradiscal pressure response to low-frequency vibration will relate to the nutrition transport. The nutrition deficiency due to vibration environment for the driver is also assumed to generate disc degeneration.

In this study, the method to measure the intradiscal pressure response to low-frequency vibration loading was developed using a calf lumbar spinal segment which is two vertebral bodies and one intervertebral disc (Functional Spinal Unit; DBU). The experiment was carried out in a physiological saline solution to simulate in vivo conditions. Pflaster et al. ${ }^{(1)}$ pointed out that the intradiscal pressure gradually reached to an equilibrium value under the static constant compression load. Therefore, before the vibration test, the equilibrium pressure was measured under the constant load during one hour. The amplitude and the frequency were controlled after the intradiscal pressure reached in an equilibrium state.

\section{Experimental Procedure}

\subsection{Specimen and experimental set-up}

In this experiment, five disc-body units dissected from the lumbar spine of 10-week-old calf were used as specimens. Posterior structures and ligaments were removed from the units. Specimens No. 1 to 3 are L2/3 spinal segment and No. 4 to 5 are L4/5 segment. Every specimen was frozen and kept at$25^{\circ} \mathrm{C}$ in a plastic bag.

The specimen was thawed just before the experiment and was prepared so that the superior and inferior surfaces were parallel to the mid-transverse plane of the disc using two plates and bone cement. The catheter pressure sensor (Mikro-tip Catheter Pressure Transducer, Millar SPR-524, Millar Instruments, Inc., Houston, TX ${ }^{(12)}$ was used to measure the intradiscal pressure. This sensor is $0.84 \mathrm{~mm}$ in diameter, and has a diaphragm at the tip of catheter, which is $1.165 \mathrm{~mm}$ in diameter and $3 \mathrm{~mm}$ in length. The pressure sensor was inserted into the center of disc nucleus through the needle (Becton Dickinson Needle No. 1209, Becton Dickinson and Company, Franklin Lakes, $\mathrm{NJ}$ ), which is $1.66 \mathrm{~mm}$ in outer diameter and $1.20 \mathrm{~mm}$ in inner diameter. Anteriorposterior and lateral radiographs were then taken to confirm the position of the pressure sensor. After that, the specimen was submerged in a physiological saline solution $(0.15 \mathrm{M}, \mathrm{NaCl})$. The lower plate of the specimen was attached to the bottom of the saline bath, and the upper plate was connected to the material testing system (858 Mini Bionix, MTS System Co., Eden Prairie, MN) through the load cell (Model 3169, Eaton Co., Cleveland, $\mathrm{OH}$ ). The experimental set-up is shown in Fig. 1.

\subsection{Loading conditions}

The effects of mean load, amplitude and frequency of cyclic loading on the intradiscal pressure response were investigated in this experiment. Table 1 lists the loading conditions. The mean loads are 20, 60 and $100 \mathrm{~N}$, and the amplitudes are 10,15 and $20 \mathrm{~N}$. The low-frequencies were selected as $0.05,0.5$ and 5 $\mathrm{Hz}$, according as drivers are subjected to low-frequency vibration up to $6 \mathrm{~Hz}^{(5)}$. Because three sets of loading condition were combined, twenty-seven vibration tests were performed on each specimen.

In order to take the equilibrium pressure into account, the constant load was applied during one hour prior to the vibration test. The equilibrium time was confirmed from the preliminary experiment. Figure 2 shows a result of the time-dependency of displacement and intradiscal pressure under the constant load of $20 \mathrm{~N}$. It is clear that the intradiscal pressure reached a constant value within one hour. Therefore, the intradiscal pressure after one hour in constant loading was defined as the equilibrium pressure. In addition, since the displacement increased with the time, the creep phenomenon was observed.

The schematic loading schedule is illustrated in Fig. 3. At first, the load was applied up to $20 \mathrm{~N}$ with the velocity of $20 \mathrm{~N} / \mathrm{s}$. The equilibrium intradiscal pressure was measured under the constant load of 20 $\mathrm{N}$ during one hour. After that, a total of nine low ${ }^{-}$ frequency vibration tests were performed with randomizing three sets of amplitudes and frequencies. Time interval of 1 minute was allowed between each test. Five load-unload cycles were repeated to be 
Table 1 Loading conditions

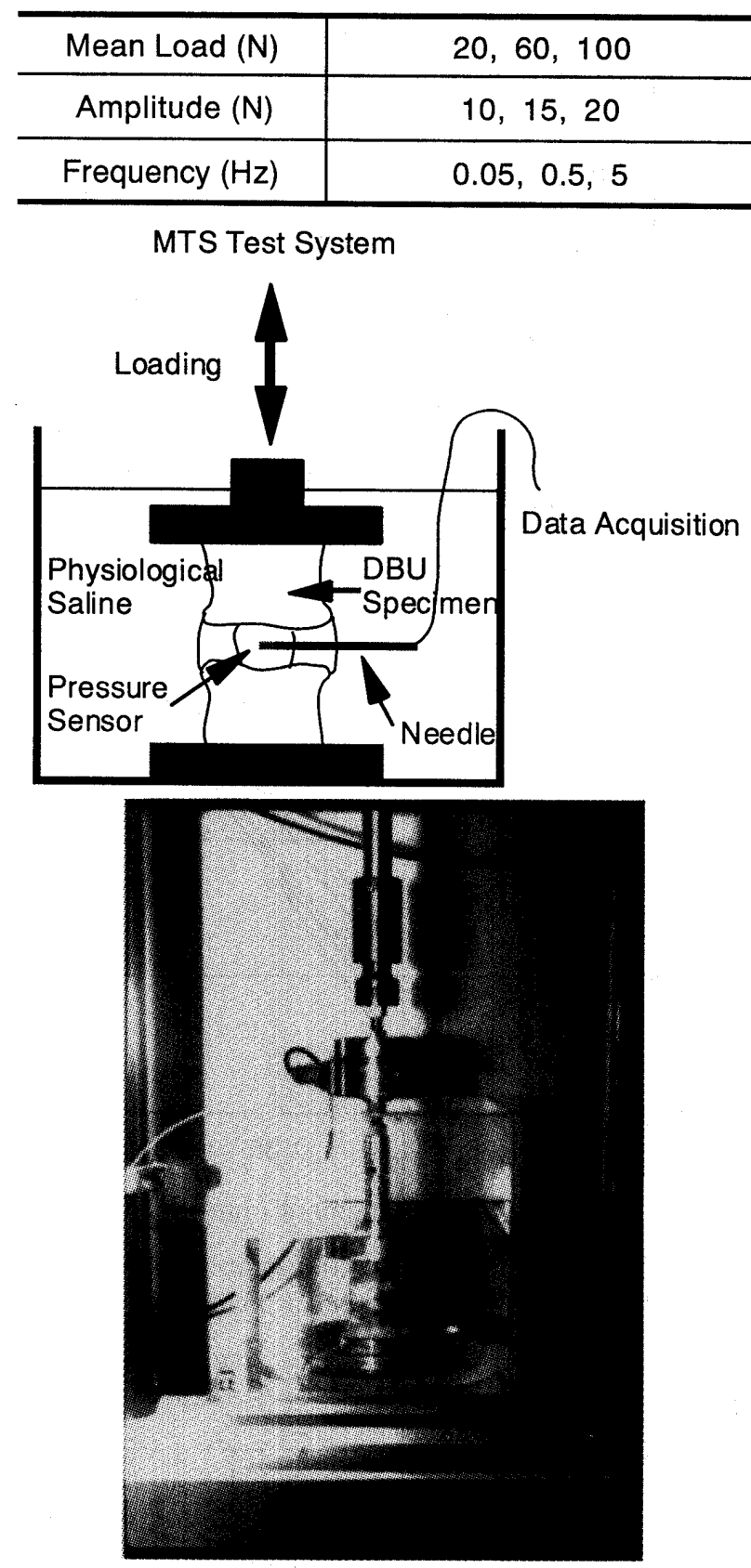

Fig. 1 Experimental set-up

saturated for successive cycles. Next, the load was applied up to $60 \mathrm{~N}$ with the velocity of $20 \mathrm{~N} / \mathrm{s}$. The equilibrium intradiscal pressure was measured under the constant load of $60 \mathrm{~N}$ during one hour. Then nine low-frequency vibration tests were also performed with randomizing three sets of amplitudes and frequencies. In the same manner, the load was applied up to $100 \mathrm{~N}$ and vibration tests were repeated.

The data of load, displacement and intradiscal pressure was sampled at every one second under the constant load. In the vibration tests, the data sampling interval was $1 / 100$ seconds of vibration frequency. The experiment was performed at room

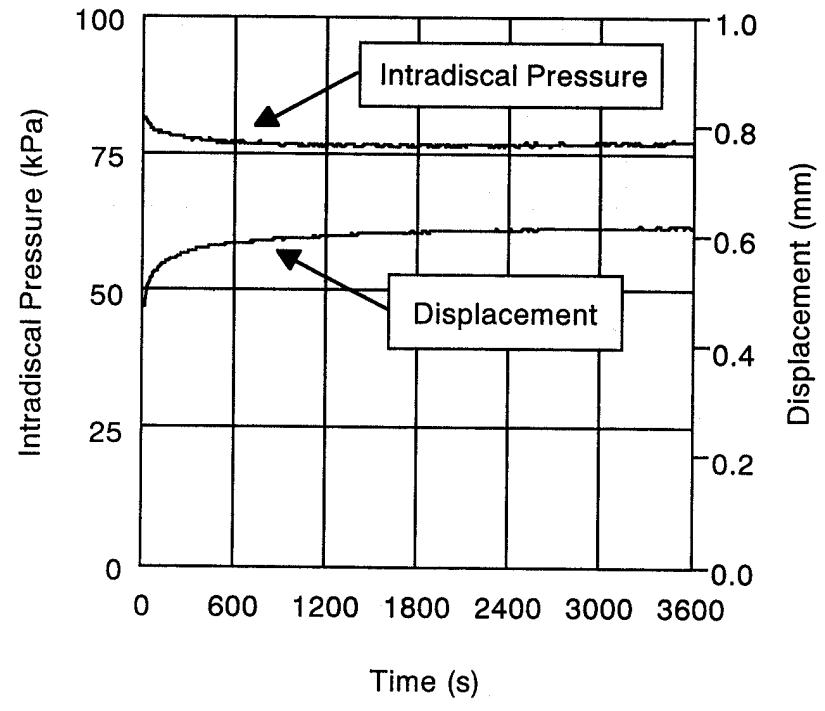

Fig. 2 The time-dependency of displacement and intradiscal pressure applied constant load of $20 \mathrm{~N}$
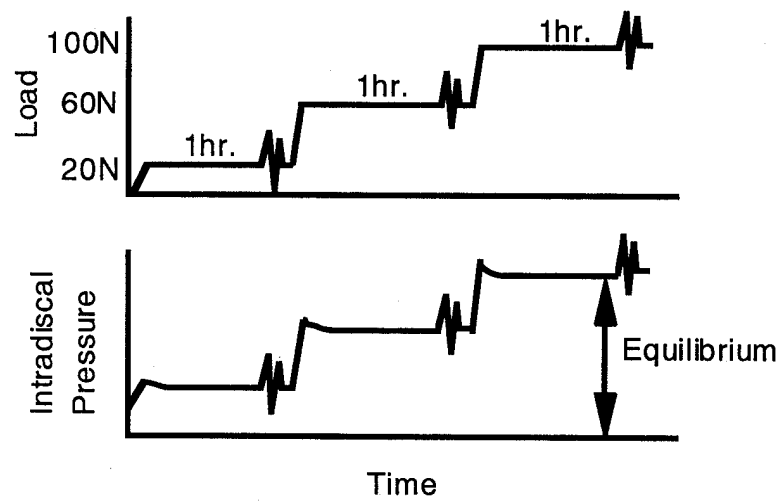

Fig. 3 Schematic loading schedule

temperature. The test duration for each specimen including the preparation of specimen was at most five hours. After the experiment, the transverse plane of the disc was cut according to the rule of pathology, and the area of cross section was measured.

\section{Results}

\section{1 Equilibrium intradiscal pressure}

The creep displacement and the equilibrium intradiscal pressure after one hour in constant loading were listed in Table 2. Here, the creep displacement is the incremental displacement just after the ramp phase. The relationship between static load and equilibrium intradiscal pressure was shown in Fig. 4. The equilibrium intradiscal pressure increased with the applied constant load. A regression analysis showed a positive linear relationship between equilibrium pressure and applied load. The following empirical equation was obtained as $(p<0.01)$,

$$
P E=0.765 F_{0}+41.0 \text {, }
$$

where, $P E$ is the equilibrium intradiscal pressure $(\mathrm{kPa})$ and $F_{0}$ is constant load $(\mathrm{N})$. 
Table 2 Creep displacement and equilibrium intradiscal pressure (PE) after 1 hour (Mean $\pm \mathrm{SD}, n=5$ )

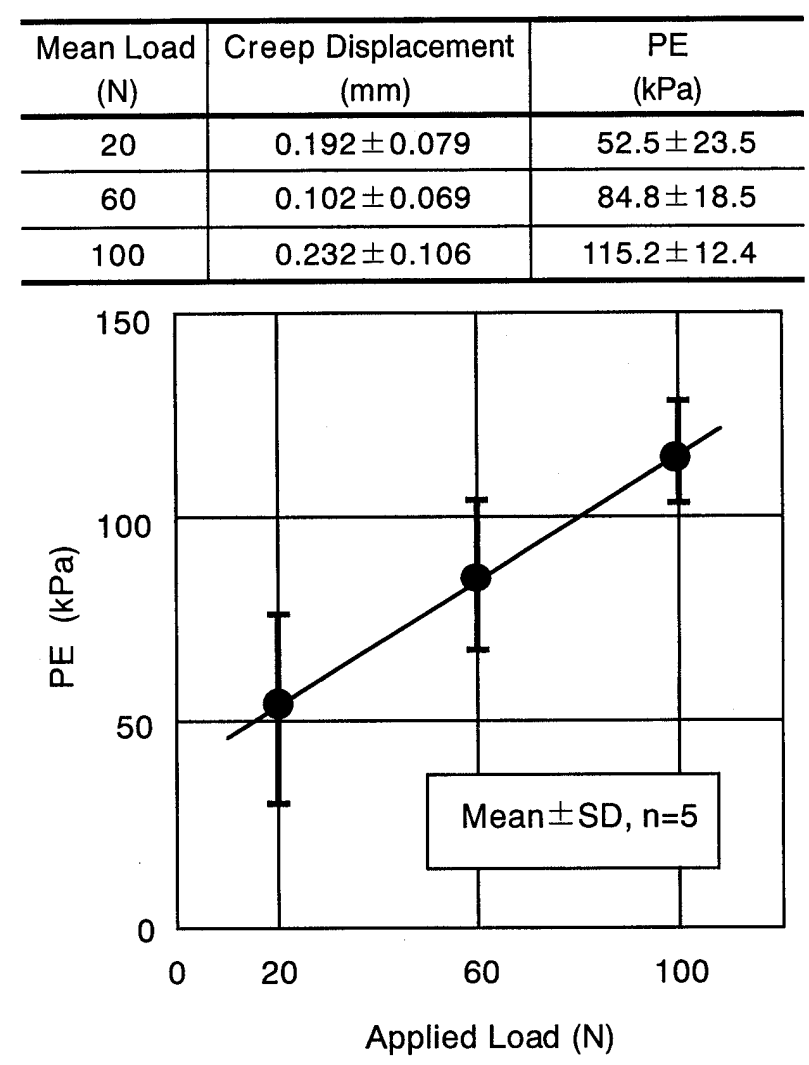

Fig. 4 The relationship between equilibrium intradiscal pressure and applied load (Mean $\pm \mathrm{SD}, n=5$ )

\subsection{Displacement response to low-frequency cyclic loading}

Figure 5 shows the relationship between load versus displacement in the fifth cycle at $100 \mathrm{~N}$ of mean load and $15 \mathrm{~N}$ of amplitude. At each vibration condition, the load-displacement relationship was saturated within five cycles. Therefore, the slope of load versus displacement could be regarded as a linear and increased with frequency. The dynamic stiffness of disc specimen was calculated by dividing the controlled peak-to-peak load by the peak-to-peak displacement. The dynamic stiffness $D S(\mathrm{~N} / \mathrm{mm})$ was defined as follows,

$$
D S=\frac{F_{\max }-F_{\min }}{D_{\max }-D_{\min }},
$$

where, $F_{\max }$ and $F_{\min }$ are the maximum and the minimum load $(\mathrm{N})$, and $D_{\max }$ and $D_{\min }$ are the maximum and the minimum displacement $(\mathrm{mm})$. The dynamic stiffness was listed in Table 3. Figure 6 is the graph of these mean values. The dynamic stiffness increased with the mean load and frequency of cyclic loading, while the effect of the amplitude was not significant. A multi-regression analysis showed a positive linear correlation between the dynamic stiffness versus mean load, and the dynamic stiffness
Table 3 Dynamic stiffness (Mean \pm SD, $n=5$ )

\begin{tabular}{c|c|ccc}
\hline Mean & Amp. & \multicolumn{3}{|c}{ Dynamic Stiffness $(\mathrm{N} / \mathrm{mm})$} \\
$(\mathrm{N})$ & $(\mathrm{N})$ & $0.05(\mathrm{~Hz})$ & $0.5(\mathrm{~Hz})$ & $5(\mathrm{~Hz})$ \\
\hline \multirow{3}{*}{20} & 10 & $325 \pm 122$ & $371 \pm 137$ & $505 \pm 208$ \\
& 15 & $291 \pm 114$ & $351 \pm 139$ & $471 \pm 208$ \\
& 20 & $258 \pm 114$ & $318 \pm 140$ & $433 \pm 197$ \\
\hline \multirow{6}{*}{60} & 10 & $691 \pm 229$ & $798 \pm 268$ & $981 \pm 370$ \\
& 15 & $646 \pm 204$ & $791 \pm 286$ & $913 \pm 327$ \\
& 20 & $627 \pm 186$ & $746 \pm 210$ & $901 \pm 237$ \\
\hline \multirow{3}{*}{100} & 10 & $1033 \pm 304$ & $1160 \pm 338$ & $1377 \pm 393$ \\
& 15 & $966 \pm 286$ & $1181 \pm 381$ & $1289 \pm 376$ \\
& 20 & $997 \pm 327$ & $1154 \pm 409$ & $1315 \pm 409$ \\
\hline
\end{tabular}

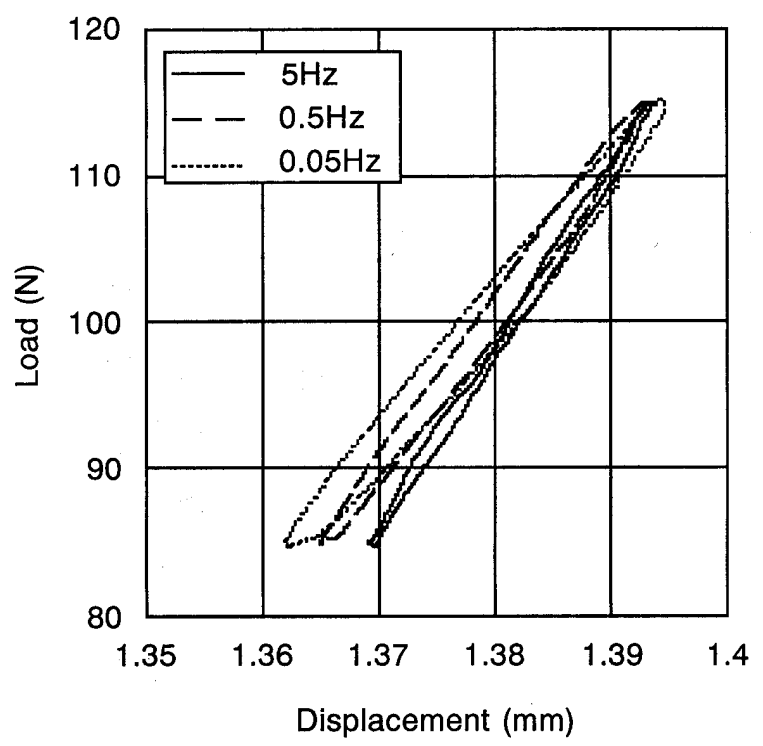

Fig. 5 The relationship between displacement and cyclic load (Specimen No. 3, Mean load $=100$ N, Amplitude $=15 \mathrm{~N}$ )

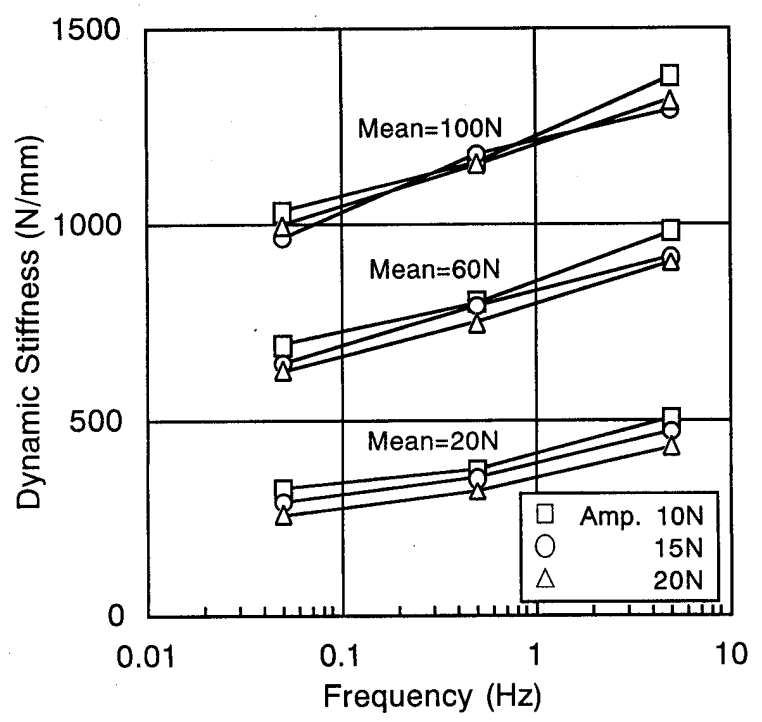

Fig. 6 The dynamic stiffness properties (Mean, $n=5$ ) 
Table 4 IDP slope (Mean $\pm \mathrm{SD}, n=5)$

\begin{tabular}{c|c|ccc}
\hline $\begin{array}{c}\text { Mean } \\
(\mathrm{N})\end{array}$ & Amp. & \multicolumn{4}{|c}{ IDP Slope $(\mathrm{kPa} / \mathrm{N})$} \\
\hline \multirow{3}{*}{20} & 10 & $0.05(\mathrm{~Hz})$ & $0.5(\mathrm{~Hz})$ & $5(\mathrm{~Hz})$ \\
\hline & 15 & $0.98 \pm 0.23$ & $0.85 \pm 0.25$ & $0.77 \pm 0.27$ \\
& 20 & $0.95 \pm 0.23$ & $0.80 \pm 0.24$ & $0.80 \pm 0.26$ \\
& 10 & $0.81 \pm 0.18$ & $0.75 \pm 0.19$ & $0.71 \pm 0.21$ \\
60 & 15 & $0.81 \pm 0.20$ & $0.76 \pm 0.22$ & $0.71 \pm 0.24$ \\
& 20 & $0.85 \pm 0.17$ & $0.81 \pm 0.18$ & $0.77 \pm 0.19$ \\
\hline \multirow{3}{*}{100} & 10 & $0.78 \pm 0.21$ & $0.72 \pm 0.24$ & $0.66 \pm 0.25$ \\
& 15 & $0.80 \pm 0.20$ & $0.74 \pm 0.24$ & $0.68 \pm 0.26$ \\
& 20 & $0.81 \pm 0.19$ & $0.75 \pm 0.22$ & $0.70 \pm 0.23$ \\
\hline
\end{tabular}

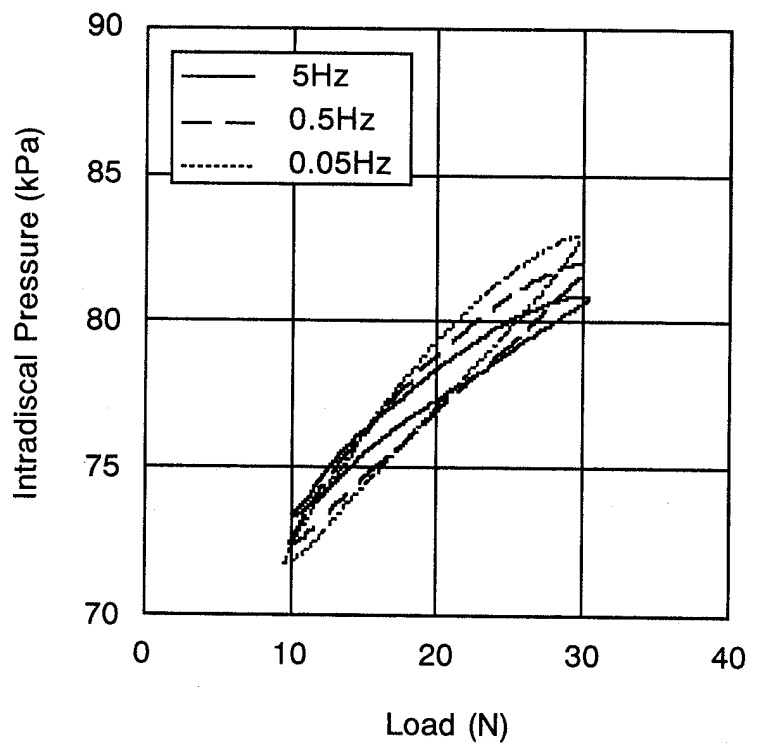

Fig. 7 The relationship between IDP and cyclic load (Specimen No. 5, Mean load $=20 \mathrm{~N}$, Amplitude $=$ $10 \mathrm{~N}$ )

versus frequency. The following empirical equation was obtained as $(p<0.01)$,

$D S=130.7 \log f+9.9 F_{0}+217.2$,

where, $f$ is frequency $(\mathrm{Hz})$.

\section{3 Intradiscal pressure response to low-fre-} quency cyclic loading

Figure 7 shows the relationship between load versus intradiscal pressure in the fifth cycle at $20 \mathrm{~N}$ of mean load and $10 \mathrm{~N}$ of amplitude. At each vibration condition, the load-intradiscal pressure relationship was also saturated within five cycles. The slope of load versus intradiscal pressure could be regarded as a linear and decreased with frequency. The IDP slope of disc specimen was calculated by dividing the peakto-peak intradiscal pressure by the controlled peakto-peak load. The IDP slope $(I S ; \mathrm{kPa} / \mathrm{N})$ was defined as Eq. (4),

$$
I S=\frac{P_{\max }-P_{\min }}{F_{\max }-F_{\min }}
$$

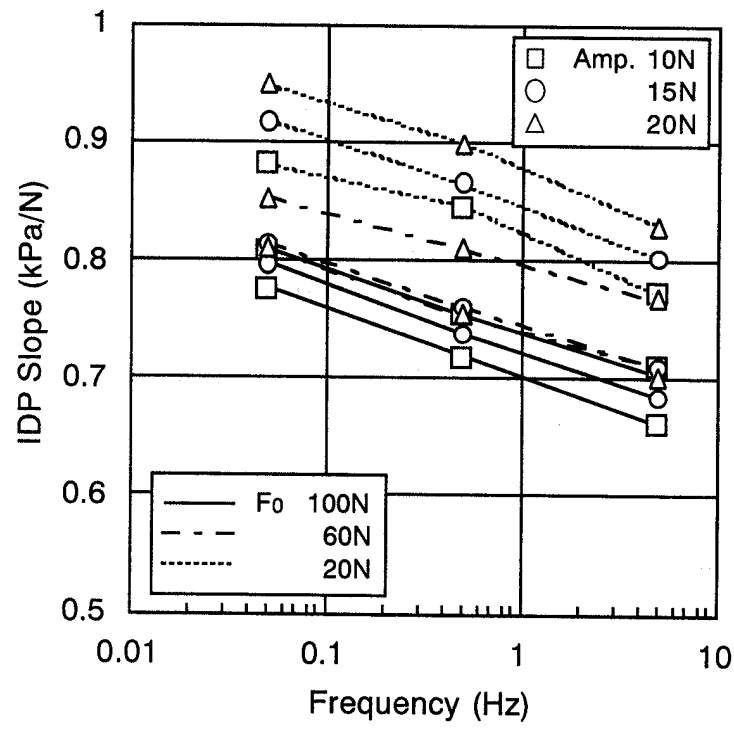

Fig. 8 The IDP slope properties (Mean, $n=5$ )

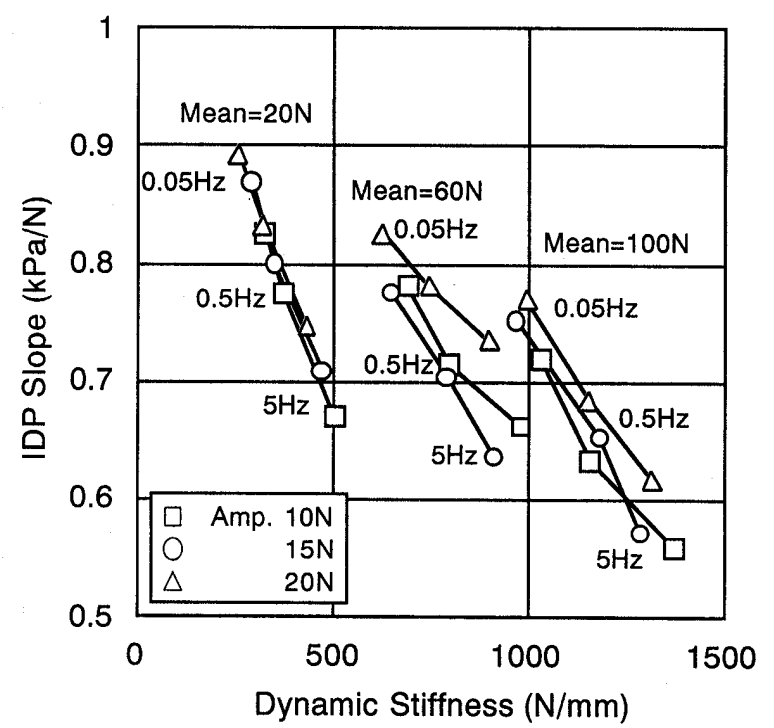

Fig. 9 The relationship between IDP slope and dynamic stiffness (Mean, $n=5$ )

where, $P_{\max }$ and $P_{\min }$ are the maximum and the minimum intradiscal pressure $(\mathrm{kPa})$. The IDP slope was shown in Table 4 and Fig. 8. The IDP slope decreased with the mean load and frequency of cyclic loading, while the effect of the amplitude was not significant. A multi-regression analysis showed a negative correlation between the IDP slope versus mean load, and frequency. The following empirical equation was obtained as Eq. ( 5$) \quad(p<0.01)$.

$$
I S=\left(-5.4 \log f-0.16 F_{0}+86.9\right) \times 10^{-2} \text {. }
$$

The relationship between IDP slope and dynamic stiffness was shown in Fig. 9. The IDP slope decreased with the dynamic stiffness and increased with the mean load and frequency, while the effect of amplitude was not significant. 


\section{Discussion}

The intradiscal pressure comes from the proteoglycan swelling because of water absorption ${ }^{(13)}$. It is thought that the intradiscal pressure plays an important role in the mechanical response to vibration. Many researchers have reported the intradiscal pressure in vivo or ex vivo since Nachemson's experiment in $1964^{(6)}$. However, no data has been reported on intradiscal pressure response to vibration loading under either in vivo or ex vivo conditions. The present study was carried out to measure the intradiscal pressure response to cyclic loading in a physiological saline solution to simulate in vivo conditions.

Pflaster et al. ${ }^{(11)}$ measured the percentage change in water content for disc specimens exposed to seven hours in a physiological saline solution under a static load of $445 \mathrm{~N}$. Within the first 0.5 hour, $75 \%$ of the overall water content increased. No significant further change occurred between 0.5 to 7 hours of static loading. They pointed out that the water content increase relates to the equilibrium intradiscal pressure. Shirasaki et al. ${ }^{(14)}$ measured the intradiscal pressure of human lumbar specimens in the air. The cyclic load of $1 \mathrm{kN}$ compression was applied with in a five second interval. At the second loading, significant intradiscal pressure decrease was observed. They suggested that the measurement might be performed in the bath of physiological saline solution rather than in the air, because nucleus fluid flew out to the annulus. In this study, the equilibrium intradiscal pressure was measured in the bath of physiological saline solution under the constant load during one hour. The cross sectional area of specimen was $2520 \pm 155 \mathrm{~mm}^{2}$ (Mean $\pm \mathrm{SD}$ ). To make a comparison between the equilibrium intradiscal pressure and applied stress, the pressure was 6.6 times the applied stress in $20 \mathrm{~N}$ compression, 3.5 times in $40 \mathrm{~N}$ and 2.8 times in $100 \mathrm{~N}$. The equilibrium pressure was higher than the applied stress. The multiplier decreased with the applied load, indicating that the water in the nucleus flows to the outside of the disc.

After the intradiscal pressure equilibrium, the dynamic stiffness and intradiscal pressure slope were investigated under the low-frequency vibration. Ishihara et al. ${ }^{(15)}$ performed vibration tests in the bath of physiological saline solution. The dynamic stiffness was compared under the vibration frequency of $3.5,10$, $35 \mathrm{~Hz}$ using porcine coccygeal discs. After vibration in six hours, significant water deficiency in the nucleus was reported on each frequency. The water deficiency may cause disc degeneration, and leads to low back pain. On behalf of the solution of the low back pain for drivers, further studies need to more understand the intradiscal pressure response to low-frequency cyclic loading in vivo.

\section{Conclusions}

This study presented a method to measure the intradiscal pressure response to low-frequency cyclic loading using calf lumbar spinal segments in a physiological saline solution to simulate in vivo condition. The following conclusions were obtained from this experiment :

(1) During one hour, the intradiscal pressure reached equilibrium under constant load. The equilibrium pressure showed the linearity to the applied load.

(2) The equilibrium pressure was higher than the applied mean stress. The multiplier (=equilibrium pressure/applied mean stress) decreased with applied load.

(3) The dynamic stiffness increased with mean load and frequency. The IDP slope decreased with mean load and frequency.

(4) The relationship between dynamic stiffness and intradiscal pressure slope was recognized.

\section{Acknowledgment}

The authors would like to thank Ram M. Gudavalli, $\mathrm{PhD}$ and James A. Baker, MD, National Laboratory of Chiropractic, for advising on the calibration of pressure sensor. This study was supported by Grant-in Aid for scientific research from the Ministry of Education, Science and Culture in Japan (No. 08458279).

\section{References}

(1) Frymoyer, J.W., Pope, M.H., Costanza, M.C., Rosen, J.C., Goggin, J.E. and Wilder, D.G., Epidemiologic Studies of Low-Back Pain, Spine, Vol. 5, No. 5 (1980), p. 419-423.

(2) Frymoyer, J.W., Pope, M.H., Clements, J.H., Wilder, D.G., McPherson, B. and Ashikaga, T., Risk Factors in Low-Back Pain., Journal of Bone \& Joint Surgery, Vol. 65-A, No. 2 (1983), p. 213-218.

(3) Kelsey, J.L. and Hardy, R.J., Driving of Motor Vehicles as a Risk Factor for Acute Herniated Lumbar Intervertebral Disc., American Journal of Epidemiology, Vol. 102, No. 1 (1975), p. 63-73.

(4) Pope, M.H. and Hansson, T., Vibration of Spine and Low Back Pain, Clinical Orthopaedics and Related Research, 279 (1992), p. 49-59.

(5) Wilder, D.G., The Biomechanics of Vibration and Low Back Pain, American Journal of Industrial Medicine, Vol. 23 (1993), p. 577-578.

(6) Nachemson, A. and Morris, J.M., In vivo Measurements of Intradiscal Pressure. Discometry, a Method for the Determination of Pressure in Lower Lumbar Discs, Journal of Bone \& Bone 
Joint Surgery, Vol. 46A (1964), p. 1077-1092.

( 7 ) Pope, M.H., Anderson, G.B.J., Frymoyer, J.W. and Chaffin, D.B., Occupational Low Back Pain: Assessment, Treatment and Prevention, (1991), p. 21-28, Mosby Year Book.

(8) Urban, J.P.G., Holm, S., Maroudas, A. and Nachemson, A., Nutrition of the Intervertebral Disc -An in vivo Study of Solute Transport-, Clinical Orthopaedics, Vol. 129 (1977), p. 101-114.

(9) Kramer, J., Pressure Dependent Fluid Shifts in the Intervertebral Disc, Orthopedic Clinics of North America, Vol. 8 (1977), p. 211-216.

(10) Hansson, T. and Holm, S.I., Clinical Implications of Vibration-Induced Changes in the Lumbar Spine, Orthopedic Clinics of North America, Vol. 22, No. 2 (1991), p 247-253.

(11) Pflaster, D.S., Krag, M.H., Jhonson, C.C., Haugh, L.D. and Pope, M.H., Effect of Test Environment on Intervertebral Disc Hydration, Spine, Vol. 22, No. 2 (1997), p. 133-139.

(12) Weinhoffer, S.L., Guyer, R.D., Herbert, M. and Griffith, S.L., Intradiscal Pressure Measurements above an Instrumented Fusion. - A Cadaveric Study, Spine, Vol. 20, No. 5 (1995), p. 526-531.

(13) Peter, G., The Biology of the Intervertebral Disc, (1988), p. 109-133, CRC Press.

(14) Shirasaki, Y., Tateishi, T., Shimokawa, A. and Miura, S., Mechanical Properties and Internal Disc Pressure of Human Intervertebral Joints, Trans. Jpn. Soc. Mech. Eng., (in Japanese), Vol. 54, No. 499, A (1988), p. 534-538.

(15) Ishihara, H., Tsuji, H., Hirabo, N., Oshima, H. and Terahata, N., Effects of Continuous Vibration on Rheological and Biological Behaviors of the Intervertebral Disc, Spine, Vol. 17, No.3S (1992), S7S12. 